\title{
GYPSUM AND LIME STABILISED EARTH-RICE HUSK COMPOSITE
}

\author{
Ana Bras ${ }^{1 *}$, Ana Antunes ${ }^{2}$, Paulina Faria ${ }^{3}$ \\ ${ }^{1}$ Built Environment and Sustainable Technologies (BEST) Research Institute, Department of \\ Built Environment, Liverpool John Moores University, Byrom Street, Liverpool, L3 3AF, \\ UK \\ ${ }^{2}$ Civil Engineering Department, FCT, NOVA University of Lisbon, Portugal \\ ${ }^{3}$ CERIS and Civil Engineering Department, FCT, NOVA University of Lisbon, Portugal
}

*Corresponding author; e-mail: a.m.armadabras@ljmu.ac.uk

\begin{abstract}
The use of environment friendly bio-based materials, with low environmental impact and low production costs could be the answer to improve the energy performance of buildings, leading to a reduction of the energy demand and cost for the building sector. This study presents the development of a novel bio-based material made with earth and reinforced with rice husk, stabilised with hemi-hydrated gypsum and air lime. The objective was to produce a highperformance composite that not only could be used as a masonry with good insulation performance but also as a regulator of the indoor air humidity. The implementation of an image analysis method enables to assess of the influence of the length and orientation of the rice husk fibres on the physical and thermal properties of the composite. In order to evaluate the influence of these factors on the performance of a bio-based material, a comparison was made with previously produced earth blocks with hemp shiv, with different natural fibre contents, different production methods and dimensions. The distribution curves obtained for the fibres length and orientation combined with fibres characterisation, highlight that the fibre length could have an influence on the thermal conductivity of the composites. Despite having a relatively low thermal conductivity, the results still do not allow the composite to be considered an insulation material but they could contribute to the indoor thermal comfort.
\end{abstract}

Keywords: clay, bio-based; mortar, fibres, gypsum, air lime, laboratory characterisation

\section{INTRODUCTION}

\subsection{Bio-Based Building Materials and 2D Image Analysis Methods}

Bio-based materials are a promising solution to optimise buildings thermal performance and environmental sustainability. They are known for having low energy requirements and low costs. They improve indoors acoustic and thermal conditions, and, on a global scale, this type 
RILEM's session 274-TCE: Testing and characterisation of earth-based building materials and elements

of materials reduces the carbon emissions once they are mainly composed by natural and available products with reduced environmental impact (Asdrubali et al. 2016).

Bio-based materials are showing promise in the race for sustainably focused alternative building refurbishment solutions, aiming to improve in-use energy efficiency and often contributing to an improvement in internal air quality (Palumbo et al. 2018). EN 16575 (2014) states that the "term bio-based product refers to products wholly or partly derived from biomass, such as plants, trees or animals."

The impact that plant-based bio-insulation materials have on the industry, and the effect they have on a buildings ecological footprint was investigated. It was found that plant-based insulation materials sequester atmospheric carbon dioxide through photosynthesis. Further stating that "typically the sequestered carbon dioxide is greater than the embodied carbon dioxide involved in their manufacture"; pointing to the notion that by using these plant-based bio-insulation materials in practice, could lead to the net embodied carbon dioxide of the building being heavily reduced and potentially resulting in a negative carbon footprint for the building (Lawrence et al. 2013) (Cetiner \& Shea, 2018) (Palumbo et al. 2018).

Through the years several authors studied the addition of natural fibres to earth composites, studying the influence of these natural aggregates on the mechanical, thermal and physical properties. Those materials properties can present an anisotropic arrangement, as it was found in bio-aggregate concretes through observations of some physical properties (Williams et al, 2016).

An increase of $30 \%$ thermal conductivity in the perpendicular direction to casting was found for cast-compressed hemp-lime specimens (Nguyen et al. 2010). Other work has reported similar findings for cast-tamped material (Dinh et al. 2015) and sprayed material (Pierre et al. 2014). In all cases, the observations were attributed to the internal structure, in which the stratified planes are opposing the transverse heat transfer.

2D analysis of composites has been used in the optimisation of the construction materials sector, namely on the characterisation of asphalt hot mixes, where the behaviour is influenced by its aggregates mechanical and geometrical properties. Since these aggregates play a very important role in the pavement stability and resistance, their characterisation should pass by the determination of length, shape, orientation and texture (Bessa et al. 2012).

Yoo et al. (2016) studied the influence of the casting method on ultra high-performance fibre reinforced concrete. During casting a unidirectional compacting force is applied to the wet material by tamping or deliberate compaction. As biofibres are often elongated in form, this compacting force is considered to have significant influence on their arrangement and the elongated particles tends towards stratified planes that are perpendicular to compacting force.

The assessment of the internal structure of bio-aggregate concretes by image analysis may be a suitable method for the assessment of these materials. Software like ImageTool, Abaqus 2008, Image $\mathbf{J}$ and the Digital Image Analysis System were referenced by Bessa et al. (2012) as commonly used for this type of analysis, being the last two the ones used by the authors. Sebaibi et al. (2014) used the ImageJ software on a cement matrix reinforced with polyester and glass fibres to analyse the number of fibres, their position and orientation. 
RILEM's session 274-TCE: Testing and characterisation of earth-based building materials and elements

The previous research works demonstrate that the thermal and mechanical properties of bioaggregate composites are anisotropic, as a result of an orientated internal arrangement of fibres. Therefore, the internal structure of earthen-fibres composite materials seems to be crucial in the optimisation of their physical properties and this has been the focus of the study presented here.

\section{MATERIALS CHARACTERISATION AND TEST PROCEDURES}

\subsection{Rice Husk -Comparison with Other Bio-Fibres}

The rice husk was provided by the company Orivárzea located in Salvaterra de Magos and characterised based on the state-of-the-art report of the RILEM TC 236-BBM (Amziane and Collet, 2016) and Laborel-Préneron et al. (2017).

Laborel-Préneron et al. (2017a) characterised hemp shiv on the work of RILEM TC 236-BBM (Amziane et al. 2017) and those were used to compare with the performance of rice husk. Hemp shiv $(\mathrm{H})$ is the by-product of the hemp defibration process and corresponds to the lignin-rich part of the stem. Based on the method used and adopting it for rice husk $(\mathrm{RH})$ characterisation, this natural aggregate was characterised regarding the bulk density, thermal conductivity and water absorption. Table 1 presents the bulk density values and water absorption for hemp shiv and rice husk.

Table 1 - Bulk density values, water adsorption and thermal conductivity for hemp shiv and rice husk fibres.

\begin{tabular}{|c|c|c|}
\cline { 2 - 3 } \multicolumn{1}{c|}{} & $\begin{array}{c}\text { Hemp shiv } \\
(\mathbf{H})\end{array}$ & $\begin{array}{c}\text { Rice husk } \\
(\mathbf{R H})\end{array}$ \\
\hline Bulk density $\left(\mathbf{k g} / \mathbf{m}^{\mathbf{3}}\right)$ & 153 & 85,09 \\
\hline Water absorption $(\boldsymbol{\%})$ & 380 & 300 \\
\hline $\begin{array}{c}\text { Thermal conductivity } \\
(\mathbf{W} /(\mathbf{m K}))\end{array}$ & 0,051 & 0,056 \\
\hline
\end{tabular}

\subsection{Earth}

The earth used is composed by quarry fines from washing aggregate sludge. The earth bulk density is $756 \mathrm{~kg} / \mathrm{m} 3$, based on EN 1097-3 (CEN, 1998). Figure 1 presents the dry earth particle size distribution curve. 
RILEM's session 274-TCE: Testing and characterisation of earth-based building materials and elements

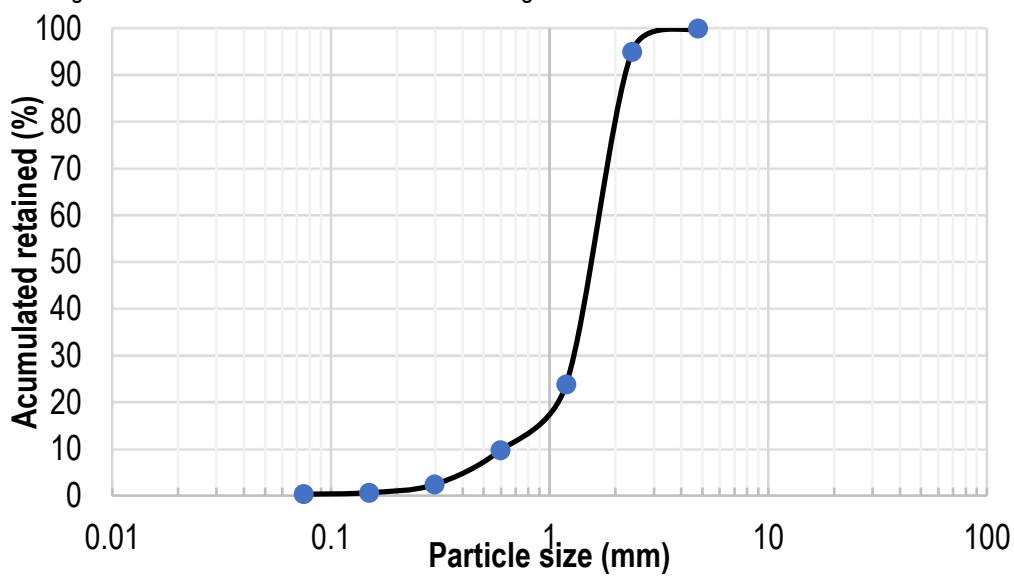

Figure 1 - Dry earth particle size distribution curve.

\subsection{Gypsum}

Gypsum used as the main stabilizer for the production of the earth panels was hemi-hydrated from Sival (Table 2). It was produced at low temperatures - between 120 and $180^{\circ} \mathrm{C}-$ and has "good thermal and sound insulation properties, with a low thermal conductivity" (Sival, 2013).

Table 2 - Hemi-hydrated gypsum properties (Sival, 2013).

\begin{tabular}{cc}
\hline \multicolumn{2}{c}{ Gypsum properties } \\
\hline Water/gypsum ration (kg/l) & 1,25 \\
Hardness time (min) & $13 \pm 4$ \\
Linear expansion (1h) $(\%)$ & $\max 0,20$
\end{tabular}

\subsection{Air Lime}

The air lime used in this work was made available by Lusical Hoist Group and its chemical composition was previously characterized by Gameiro et al. (2014) -Table 3.

Table 3 - Chemical composition of air lime (Gameiro et al. 2014).

\begin{tabular}{|c|c|c|c|c|c|c|c|c|c|c|c|}
\hline$(\%)$ & $\mathbf{S I O}_{2}$ & $\mathbf{A l}_{2} \mathbf{O}_{3}$ & $\mathbf{F e}_{2} \mathbf{O}_{3}$ & $\mathbf{M n O}$ & $\mathbf{M g O}$ & $\mathbf{C a O}$ & $\mathbf{N a}_{2} \mathbf{O}$ & $\mathbf{K}_{2} \mathbf{O}$ & $\mathbf{T i O}_{2}$ & $\mathbf{P}_{2} \mathrm{O}_{5}$ & $\begin{array}{c}\text { Loss on } \\
\text { ignition }\end{array}$ \\
\hline $\begin{array}{c}\text { Air } \\
\text { lime }\end{array}$ & - & 0.01 & 0.15 & 0.01 & 3.09 & 76.74 & - & 0.02 & 0.04 & 0.01 & 20.45 \\
\hline
\end{tabular}

\section{PANELS PRODUCTION}

Specimens for the different tests were prepared by two different casting methods for the manufacturing of blocks with a fibre content of $3 \%$ (in weight): method one for 20x20x $5 \mathrm{~cm}^{3}$ unstabilised statically compressed earth blocks with hemp shiv and rice husk, and method 2 for $20 \times 20 \times 4 \mathrm{~cm}^{3}$ gypsum and air lime stabilised hand moulded earth blocks with the same rice husk as before. 
RILEM's session 274-TCE: Testing and characterisation of earth-based building materials and elements

The water contents of the mixtures for $5 \mathrm{~cm}$ thickness compressed blocks were determined by the Proctor test, and then rounded up because this is a minimum value for manufacturing compressed earth bricks (Laborel-Préneron et al. 2017b); Laborel-Préneron et al. 2018). For this 1 st method, as it was expected, the water content of the dry mass needed to make the mixtures was higher for straw than for hemp and rice husk because straw particles have a higher water absorption coefficient than the other two aggregates (Table 1).

In the second casting process for the $4 \mathrm{~cm}$ thickness moulded blocks production, the dry ingredients - earth, gypsum and lime - were mixed with a shovel. Water was then added while mixing with a mechanical mixer until the mixture was homogenised letting the mixture to flow into the mould. Since the composition includes gypsum, which has a very quick hardening process, the protocol was based on Lima et al. (2016) and the earth-binder-water mixture was mixed during 90 seconds. The rice husk was then added to the mixture and mixed mechanically with the same device until a homogeneous consistency was obtained (around 1 minute). The specimens were casted on $20 \times 20 \times 4 \mathrm{~cm}^{3}$ wooden moulds. To simplify and to avoid fractures on the demoulding process, a transparent plastic paper was wrapped around the wooden moulds. The specimens were casted on 20x20x4 cm wooden moulds.

\section{RESULTS AND DISCUSSION}

The fibre length and orientation of 20x20x4 and $5 \mathrm{~cm}$ blocks were measured using a 2D Image analysis software for all the compositions (hemp shiv and rice husk with the two different thicknesses). It enabled to calculate an average and frequency distribution of the obtained results.

First it was taken a high-quality picture with a 15 megapixels' camera; then the contrast was slightly adjusted for better perception of the fibres outline from the earthen matrix. Resourcing to ImageJ a scale was set based on the horizontal dimension of the blocks; finally, the length and the angle of orientation with the horizontal plane were measured for each fibre (Figure 2).

The objective was to determine the influence of fibre length and orientation on the thermal conductivity and ultra sound propagation properties of the earth blocks. It is important to retain that this method is made manually for about 400 fibres in each surface; whereby there is an error associated to these measurements.
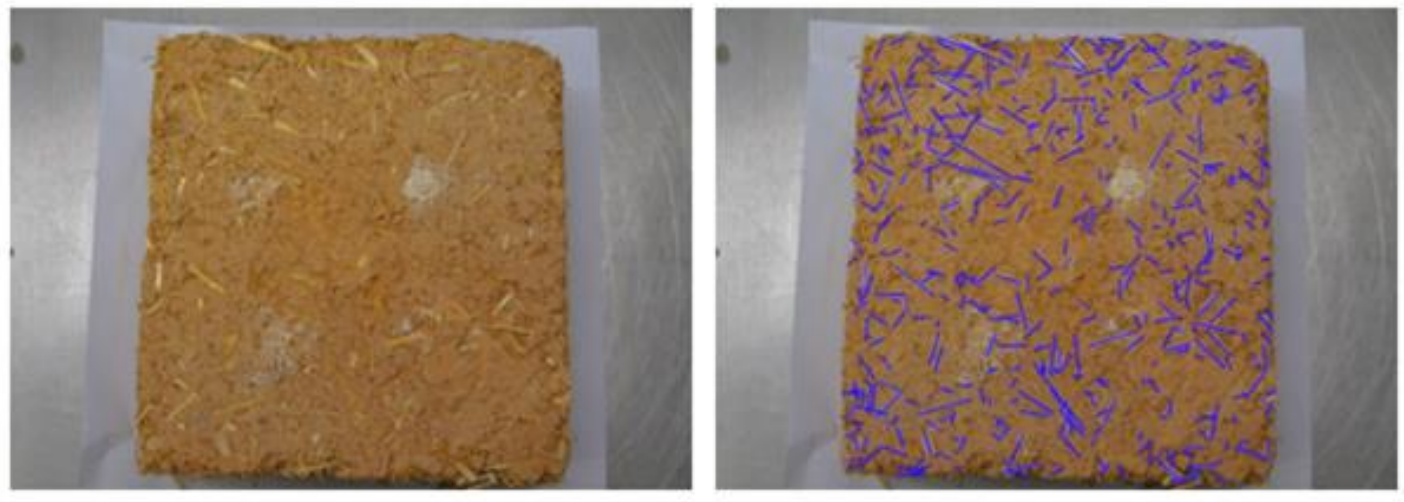

Figure 2 - Example of a block before and after Image $\mathrm{J}$ analysis. 
RILEM's session 274-TCE: Testing and characterisation of earth-based building materials and elements

The following figures show the fibre length and orientation angle orientation distribution (frequency in bars, cumulative distribution in lines) for rice husk blocks with 4 and $5 \mathrm{~cm}$ thickness and hemp shiv blocks (for comparison).

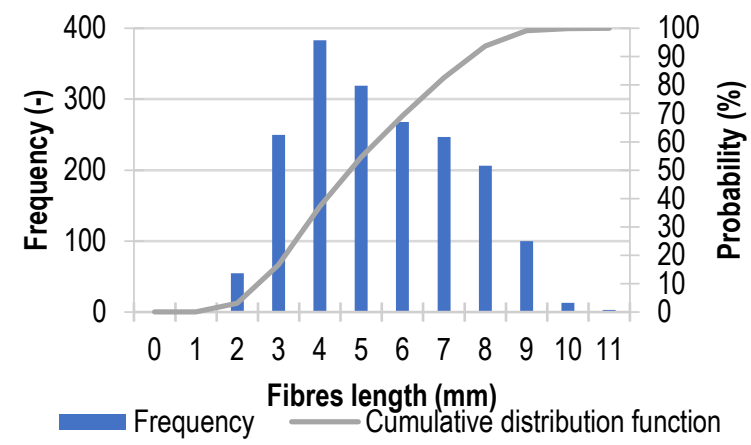

Figure 3a - Fibre length distribution for rice husk blocks with $5 \mathrm{~cm}$ thickness.

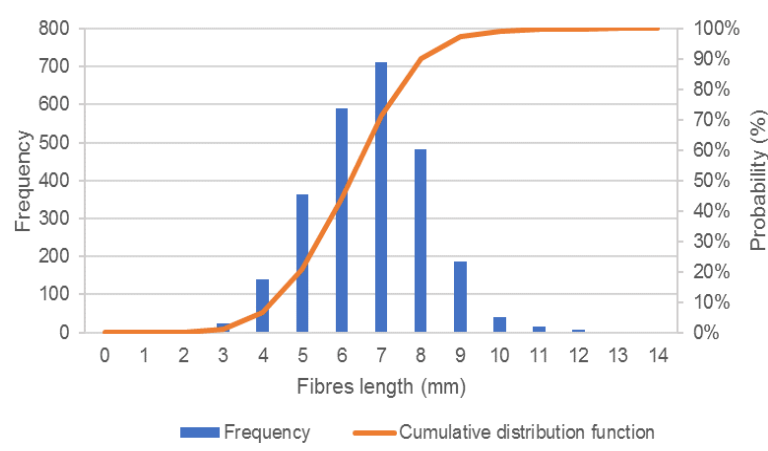

Figure 4a - Fibre length distribution for rice husk blocks with $4 \mathrm{~cm}$ thickness.

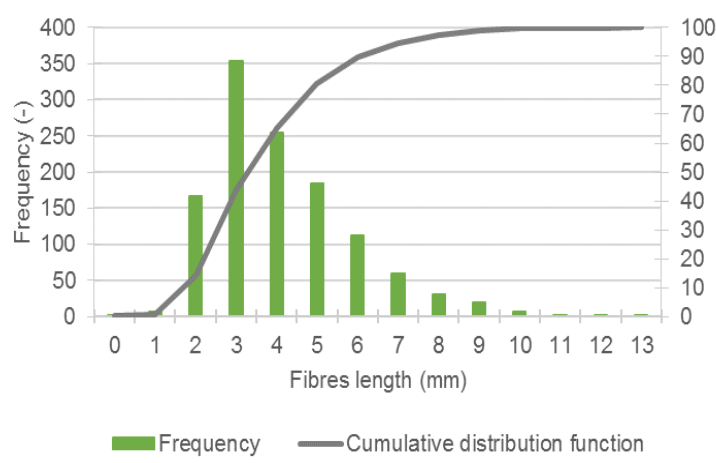

Figure 5a - Fibre length distribution for hemp shiv $5 \mathrm{~cm}$ thickness blocks.

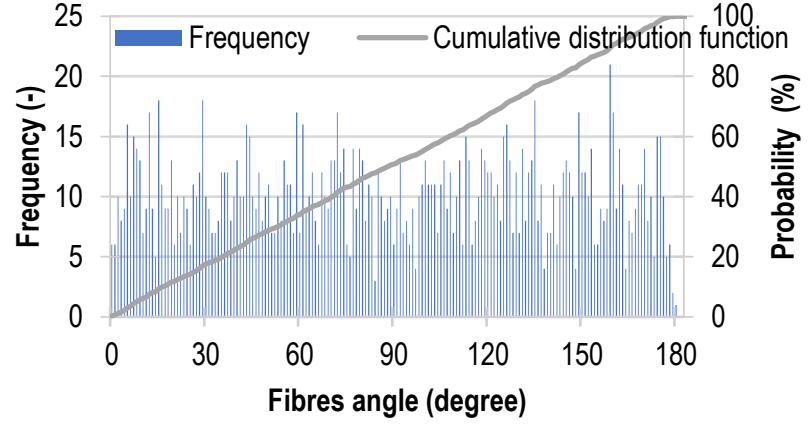

Figure $3 b$ - Fibre angle distribution for rice husk blocks with $5 \mathrm{~cm}$ thickness.

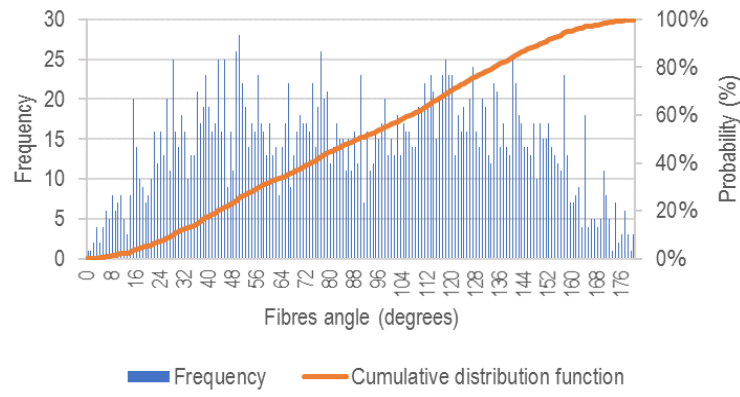

Figure $4 b$ - Fibre angle distribution for rice husk blocks with $4 \mathrm{~cm}$ thickness

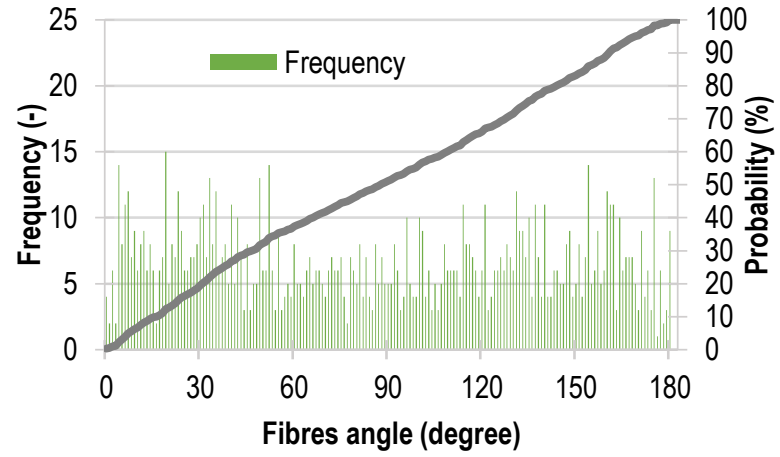

Figure $5 b$ - Fibre angle distribution for hemp shiv $5 \mathrm{~cm}$ thickness blocks. 
RILEM's session 274-TCE: Testing and characterisation of earth-based building materials and elements

The previous figures show that the probability of achieving a specific fibre length tends to a lognormal distribution. Beside this, a uniform distribution is detected for the fibre angle distribution, meaning that the probability of achieving a fibre angle orientation between $0^{\circ}$ or $90^{\circ}$ degrees is the same for Figs $3 \mathrm{~b}$ and $5 \mathrm{~b}$. Figure $4 \mathrm{~b}$ demonstrates that the fibre orientation distribution is not uniform and so the probability of achieving a fibre angle orientation of $0^{\circ}$ or $90^{\circ}$ is not the same. The average length of hemp shiv fibres is around $3.5 \mathrm{~mm}$.

Figures 3a and Figure 4a show that the different casting of the products has stronger influence on the fibre length, although the same type of fibre was used in both compositions. The different casting methods used for the rice husk blocks with a thickness of $4 \mathrm{~cm}$ and $5 \mathrm{~cm}$ can break the fibres $(5 \mathrm{~mm}$ length in the compressed blocks, with higher thickness, and $6 \mathrm{~mm}$ in the moulded ones, with $4 \mathrm{~cm}$ ), leading to different physical characteristics. It is also possible to see that an optimised casting method, as the one used on the rice husk blocks with $4 \mathrm{~cm}$, could lead to a more homogeneous fibre distribution and microstructure, although to a lower compaction.

Making a comparison with the distribution curves obtained for the fibres length and orientation (Figs. 3a to 5b) combined with fibres characterisation (table 1), it is possible to see that the fibre length could have an influence on the thermal conductivity of the composites. Rice husk thermal conductivity is higher than for hemp shiv, but an optimised casting method can lead to a substantial thermal conductivity reduction of the block composite $(0,102 \mathrm{~W} /(\mathrm{mK}))$.

\section{CONCLUSION}

The distribution curves obtained for the fibres length and orientation (Figs. 3a to 5b) combined with fibres characterisation (table 1), highlight that the fibre length could have an influence on the thermal conductivity of the composites. Rice husk thermal conductivity is higher than for hemp shiv, but an optimised casting method can lead to a substantial thermal conductivity reduction.

Rice husk bocks show that the casting method can have a strong influence on the fibres orientation. The fibre orientation distribution is not always uniform in the bio-based composite tested and the probability of achieving a fibre angle of $0^{\circ}$ or $90^{\circ}$ is not the same.

The geometrical properties of natural fibres seem to be directly connected to the bulk density of the earth blocks: the bigger the fibres, the lower the bulk density, leading to lower thermal conductivity of the composite.

\section{REFERENCES}

Asdrubali, F., Bianchi, F., Cotana, F., D’Alessandro, F., Pertosa, M., Pisello, A. L., \& Schiavoni, S. (2016). Experimental thermo-acoustic characterisation of innovative common reed bio-based panels for building envelope. Building and Environment, 102, 217-229. https://doi.org/10.1016/j.buildenv.2016.03.022

Palumbo, M. Lacasta A.M. Giraldo, M.P. Haurie, L. Correal, E. (2018) Bio-based insulation materials and their hygrothermal performance in a building envelope system. Energy \& Buildings, 174(1), 147-155 
RILEM's session 274-TCE: Testing and characterisation of earth-based building materials and elements

EN 16575 - Bio-based products [Online] Available at: https://www.en-standard.eu/csnen-16575-bio-based-products-vocabulary/.

Lawrence, M, Shea, A, Walker, P \& De Wilde, P (2013) Hygrothermal performance of bio-based insulation materials' Proceedings of the Institution of Civil Engineers:

Construction Materials, 166(4) 257-263.

Cetiner, I. Shea, A. (2018) Wood waste as an alternative thermal insulation for buildings. Energy \& Buildings, 168(1) 374-384.

Williams, J., Lawrence, M., Walker, P. (2016). A method for the assessment of the internal structure of bio-aggregate concretes, Construction and Building Materials, 116, 45-51, https://doi.org/10.1016/j.conbuildmat.2016.04.088

Nguyen, T.T., Picandet, V., Carre, P., Lecompte, T., Amziane, S., Baley, C. (2010). Effect of compaction on mechanical and thermal properties of hemp concrete, Eur. J. Environ. Civ. Eng. 14 (5), 545-560. https://doi.org/10.1080/19648189.2010.9693246

Dinh, T.; Magniont, C., Coutand, M., Escadeillas, G. (2015). Hemp concrete using innovative pozzolanic binder. 1st International Conference on Bio-based Building Materials, Clermont-Ferrand, France.

Pierre, T., Colinart, T., Glouannec, P. (2014). Measurement of thermal properties of biosourced building materials, Int. J. Thermophys. 35 (9-10), 1832-1852. https://doi.org/10.1007/s10765-013-1477-0

Bessa, I. S., Castelo Branco, V. T. F., \& Soares, J. B. (2012). Evaluation of different digital image processing software for aggregates and hot mix asphalt characterisations. Construction and Building Materials, 37, 370-378. https://doi.org/10.1016/j.conbuildmat.2012.07.051

Yoo, D. Y., Banthia, N., Kang, S. T., \& Yoon, Y. S. (2016). Effect of fiber orientation on the rate-dependent flexural behavior of ultra-high-performance fiber-reinforced concrete. Composite Structures, 157, 62-70. https://doi.org/10.1016/j.compstruct.2016.08.023

Sebaibi, N., Benzerzour, M., \& Abriak, N. E. (2014). Influence of the distribution and orientation of fibres in a reinforced concrete with waste fibres and powders. Construction and Building Materials, 65, 254-263. https://doi.org/10.1016/j.conbuildmat.2014.04.134 